\title{
Time Management in Social Networking Sites and Its Role in Preventing the Risk of Addiction to These Sites Among Its Users
}

\author{
Dr. Maryam Abdel-Rahman Abdel-Al \\ Yarmouk University
}

\begin{abstract}
:
This study aimed to identify time management in social networking sites and its role in preventing the risk of addiction to these sites among its users. The researcher used a descriptive survey method based on data and information collection tools (analysis of documents and records) to answer the questions of the study. The study sample consisted of (412) male and female university students which was chosen based on simple random selection from (Yarmouk University, Jadara University, Irbid National university. For achieving the purposes of the study, the researcher developed the study tool (questionnaire) which is consisted of (22) items. After verifying its reliability and validity the researcher calculated the means, standard deviations, frequency and percentages. The results showed that the role of time management in social networking sites in preventing the risk of addiction to these sites among its users ranged from (moderate - very high). The results also showed that there was a statistically significant difference to the estimates of the members of the study sample on time management in social networking sites and its role in preventing the risk of addiction to these sites among users from the university students as a whole. It is attributed to the gender variable in favor of males and for the school year variable. The results showed that there was no statistically significant difference for the study sample due to the college variable. Keywords: time, time management, social networking sites (SNS), addiction.
\end{abstract}

DOI: $10.7176 / \mathrm{JEP} / 11-8-19$

Publication date:March $31^{\text {st }} 2020$

\section{Introduction}

Time is a very important resource that a person should invest, for this reason all human civilizations stressed on the importance of time. Philosophers and wise men warned against the danger of losing time, and in our Islamic religion we found that the Messenger of Allah peace be upon him stressed deeply on the danger of wasting time by saying: "There are two blessings in which many people incur loss. (They are.) Health and free time (for doing good). "Actually, there is no sane person wastes his time purposefully, because it kills his life as it is known that time waits for no-one. The great scientist Hassan al - Basri said " $\mathrm{O}$ son of Adam, you are like days, if your day is gone, you will be gone too. "In fact, a rational person uses his time in an orderly and ideal way and doesn't spend his time aimlessly ( Faqi, 2008).

Millions of people around the world spend hours during the day scrolling and checking their accounts on social media which affects their life. Various studies published in Arab and European countries have pointed to the negative effects of this phenomenon on a person who spends a long time on social networking sites ( SNS) that often expose him to loneliness, isolation from the family, feeling of tension, physical inactivity and depression, etc.

Many media experts found that the long-time people spend on SNS is more than the benefits these websites gain. It also consumes time at the expense of carrying out other activities or performing their responsibilities. Many site addicts spend time unconcerned with their responsibility towards their families, job or their social duties in their real life. Many psychiatrists also warn about the impact of fake communication on SNS on an individual's psyche. This means the time a person spends between virtual pages is in fact a fake time and without any desired benefit (Rafaya, 2016). According to Adarbeh ( 2006) time has gained importance for man because it is an important dynamic dimension in his life that he cannot control, and because it is the vessel that embraces all human interactions and productions, and because it is the life itself, since life is the amount of time that man lives from birth until his death. Therefore, many specialists regard the time as the most important element of life and SNS have become a significant alternative to real life. Underestimating its impact or consider it just a kind of entertainment can lead to catastrophic results as some users of SNS completely abandon their real life by creating a parallel life via social networking sites, this may lead to loneliness, isolation (reverse expected) and thus to serious degrees of anxiety and depression. Some ways and means of organizing, managing and controlling time when using social media as mentioned by Hamdi (2016.)

- Understand your behavior: the beginning is to know your behavior and habits towards social media sites, to know how much time you spend daily or weekly on these networks. You will be able to see the time spent in the corridors of these networks, and then begin to develop solutions.

- Specific times: Try to determine the time you will spend within any social platforms before you enter it.

- Stop alerts: One of the things that attracts us to the world of social platforms; alerts that appear in our smartphones, stopping some or all of these alerts, especially on smart phones that accompany us 
everywhere we go help reducing the time lost on these networks.

- Connect your accounts to each other: select one social network that you prefer to write in and interact with others in it, and then connect the rest of the social networks to this network, so that you write and publish in one network and these posts appear in the rest of the networks automatically.

- Get out of groups: Get out of groups that do not interest you, that you have become a member of dozens of groups on Facebook and you do not know who entered you.

- Read only: If you are the one who responds to each post on Facebook or every tweet on twitter, it will take you a lot of time every day, so be used to not respond unless it is necessary.

Social networking sites have spread widely and become the largest sites in the web space, it expanded its services and provided its browsers with broad possibilities in the exchange of information in different fields of education, culture, sports and others. Every person is responsible for determining how to spend his time in social networking sites. Will he benefit from the scientific sites and its good content? Or will he waste his time on the different social networking platforms?

Those who participate in scientific, political, cultural, and social knowledge will increase their awareness and knowledge at the same time, they will contribute to enrich these sites with the knowledge they possess for the benefit of others. On the other hand, there are other sites that have their followers, which call for the dismantling of the social fabric to sow sectarianism, terrorism, violence, crime and the sexual sites that lead to degradation of morality and virtue (Meligi, 2015).

Social networking sites are a modern means of communication through (SNS) millions of Internet users communicate with each other without being separated by any factors such as age, gender, occupation or nationality. Users of these sites share a common interest and hobbies.

Adolescents and young adults are usually more vulnerable to these sites. They have embraced these sites much more than the older generations, to connect with their peers, share information, reinvent their personality and showcase their social lives. They are usually more prone to develop addictive behaviors to SNS, as they are habitually alert to what happens in these virtual environments and because of their growing interest in the use of modern technology especially the social networks site. It is also due to some psychological and social factors represented in the desire of young people to establish relationships and friendships with others in different countries of the world (Boyd and Ellison, 2007) .also due to some psychological and social factors represented in the desire of young people to establish relationships and friendships with others in different countries of the world (Boyd and Ellison, 2007). There are very popular social networking sites visited and used by millions of people (Elise,2017) and (Antony,2016.) which are:

1- Facebook: It has more than one billion users per month and is considered the largest social networking platform on the Internet, and it was established in 2004

2- Twitter: It has more than 300 million users per month, and its users can publish posts within a maximum of 140 characters. Companies use twitter to communicate with its customers publishing news about their products.

3- Google Plus: It owns more than 400 million active users per month and it in use in 2011

4- YouTube: It is the largest social networking platform with more than one billion visitors per month. It is specialized in downloading, uploading and watching video clips. It was established in 2005, then Google purchased it with $\$ 1$ billion of $\$ 65$ billion.

5- Instagram: It is a website of the Facebook company and has more than 400 million visitors. It offers its users many tools to edit photos and videos.

6- Snapchat: is a multimedia messaging app used globally. It was published in 2011 and according to statistics conducted in 2015, it has a hundred million active users daily.

7- WhatsApp: It is an application for smartphones, tablets and computers. It allows users to create conversations with other users and enable them to send pictures, audio, video clips in addition to document files. It was published in 2010 and has more than one billion users.

McClellan (2012) provided six ways employed in the treatment of disorder of social media addiction, the most important of which are: 1- determining the goals of the individual for accessing the social networking sites. 2- Determining the time, he allocated to achieve those goals while browsing. 3- Making the social media site share the individual's goals and works with him and not in the opposite direction.4- Taking breaks from social media. 5Using these sites as a source of stimulation and rewarding for the individual after doing a good work or carrying out a successful project. 6- Using it for exercising a sport, artistic hobbies or going out to meet friends or family.

\subsection{Signs of social networking addiction as stated by Najem (2012).}

The interest in the study of Internet addiction as a phenomenon has spread among individuals in different communities, perhaps it is due to the multiple impacts it has on its users such as psychological, social and health impacts. In fact, Internet users spend most of their time online thus they devote less time to perform another activity or to communicate with others which may have a toll on their life.

At the same time, we shouldn't ignore the great role these sites play. They provide a huge amount of 
information at an amazing speed and they have contributed in diminishing the distance between friends and families, they also made the world as a small village where its people interact with each other easily. Najem (2012) pointed out the signs of social networking addiction, which are:

- Spending several hours, a day on social media.

- Browsing social media whenever possible.

- Over-participating on these sites.

- Affecting the individual's professional, academic or social performance.

- The appearance of psychiatric symptoms such as withdrawal when trying to reduce the time of surfing of communication sites

- $\quad$ Resorting to networking sites to avoid problems that occur in real life.

- Browsing social networking sites when going to sleep causing insomnia, accessing these sites directly when wake up and remains in a constant watch.

- Severing anxiety and tension in the case of an impediment to communication, and a sense of great happiness when returning.

1.2 The effects of social networking addiction as stated by Waleed (2019):

A) Physical effects: Carpal tunnel syndrome is a medical condition affecting the hands or wrists due to too much writing and compression on fingers because of too much typing on the phone. Eye strain as a result of staring at the screen for too long.

B) Psychological and mental effects: low self-esteem, feelings of envy when looking at the lives of others that seem perfect on social media and unwillingness to have real social interactions if one thing can be said to hundreds of people with a single click. The preoccupation of mind in things that are not beneficial rather than learning something new, and wasting time on these sites leads to complete separation from the outside world over time, in addition to neglecting the realistic communication with close friends and family, which affects the addict of those sites in a state of loneliness and isolation.

The findings of some research have also shown that addiction to the use of social media impacts not only the addicted negatively or his health in the future, but also leads to the deterioration of their social relations and personal lives, because its results are not only limited to the loss of moral responsibility towards themselves and their society. Actually, the danger is that addicted social media will replace their fundamental values with alternate values that may not be consistent with their culture or religion Which in return may affect his psychological and personality structures (Raymer,2015.)

Both Internet and Facebook addiction have negative effects on the life of the individual and society, especially on the group of youth and adolescents category who are the most category exposed to this type of addiction (Abu Hadrous, 2016) ,) Adolescences waste their time at the expense of other activities or responsibilities that must accomplished, many site users spend most of their time following these social platforms, ignoring their obligation for their families, jobs or social responsibilities in the real world

Most psychological experts warn about the impact of fake contact on the individual's psyche on these sites and waste fake time jumping from one site to another with no desired benefit. The long-term risk of using these sites comes from stealing the people's age in a faked world that is related to some attitudes and topics presented on the sites that may influence the person's awareness as well. Overcoming Internet platforms addiction requires a strong will just as any other addiction that requires effort and determination, and the first step is to recognize the risks of spending long hours a day on social networks with no logical purpose (Al-Faqi, 2008.)

Educators realized the importance and seriousness of social media which driven them to conduct several studies on this topic. According to recent studies conducted in 2010 that the number of Arab users of the site "Facebook" reaches more than 15 million people, and studies also indicated that the number of Arab users is increasing at a rate of one million Person every month. Facebook, for example, is one of the most popular social networking sites platforms which was established in 2004 with several users exceeds 21 million. (Abu Hadrous, 2016.)

Social media is characterized by being a society that is based on invisible or indirect relationships. It gives an individual the opportunity to communicate with the largest possible number of individuals, it does not require social skills to manage relationships, it is sometimes encourages people to live in an imaginary world which they does not real have but pretend so, even if it lasted for a short time (Al-Shimi, 2009.)

The phenomenon of addiction to social networks has become a concern for millions of users around the world because of their negative effect on health and psychological damage it causes. Addiction to SNS takes many forms such as continuous browsing of these sites, addiction to electronic games, sending text messages "Chat" and taking lots of photos "Selfie" (Naif, 2018).

Addiction to these sites has become a state of disease as the non-consensual use of the Internet leads to behavioral disorders, as evidenced by several phenomena, including increasing the number of hours in front of the 
computer and sitting in front of the network, despite the existence of problems such as sleeplessness, insomnia, social isolation, neglect of family duties and loneliness and reluctance of the community, in addition to the extreme tension and anxiety in the case of an impediment of communication.

Therefore, it is necessary to work on finding ways to reduce this phenomenon and preventing its seriousness to the individual and society through the work of studies dealing with the subject of addiction. Scholars should also find ways to solve this problem, for these reasons this study, entitled "Time Management on social networking sites and its role in preventing the risk of addiction to this Sites among their users." came to discuss this phenomenon and to find solutions.

\section{Previous studies}

Al-Helo (2018) study aimed to reveal the effect of social media overuse on the psychology of the Arab university student. The researcher built a questionnaire on the subject and contacted universities in Arab countries to expand the sample scope. The sample included students from the following countries: The Republic of Lebanon, Saudi Arabia, Jordan and Palestine. The sample of the study consisted of (668) students. The results showed that there were statistically significant differences between the environmental characteristics of Arab youth, according to the country, in terms of the achieved satisfaction using social media. It was also found that the use of these sites enhances the sense of social presence. The results also indicated a statistically significant relationship between the daily rate of social media use, cyber addiction and frustration. As for some friends 'practices on social media sites, the study revealed that these practices include, blocking, deception, lying, insults, and defamation which leads the university youth to feel frustrated.

Marrakech (2014) study aimed to reveal the nature of the relationship between the use of social media "Facebook" and the feeling of loneliness to a sample of students of the University of Mohammed Khader - Biskra - and studying the potential impact of each of the following variables: gender, age, on the students use of the social media site "Facebook" and feeling of loneliness. Through this study, the researcher sought to know the habits of the university student when using the "Facebook", as well as to identify the fields and services he preferred on the site. The researcher used the descriptive and analytical correlative methodology. The two study tools, the scale of Facebook use, which was prepared by the researcher, and the UCLA loneliness scale were applied to a sample of (240) students, to detect the differences between the scores of two groups or more of (age groups) .

The study revealed the following results: University students spend most of their time using the site "Facebook", especially in their spare time most of them browse the site more than three hours a day. The result showed that the most preferred applications of the university students on the site "Facebook" is chatting and communicating with friends. The results also showed that there is a positive correlation between the use of social media site "Facebook" and the feeling of loneliness among university students.

Sharifah et al., (2011) study identify the relationship between female students' motives for Facebook use and Facebook addiction. This study involved (380) female students (Facebook users) from University Kebangsaan Malaysia and University Tenaga National. Findings of the study showed that there was significant relationship between female students' motives for Facebook use and Facebook addiction. It also showed that social interaction, passing time, entertainment, companionship and communication motives were among the major contributors to the addiction of Facebook site.

The study of Mecheel (2010) aimed to investigate the impact of the use of social networks on social relations. The study was applied to a sample of (6144) young network users in Britain. The results showed that more than half of adults who use sites including Facebook and YouTube, admitted that they spend more time on the Internet than they do with their real friends or family members. The study indicated that they talked less on the phone. They do not watch television much, play fewer computer games, and about (12\%) of those surveyed admit that social networks have already changed their lifestyles.

Kraut et al., (2007) This study is about "the impact of the use of the Internet on social interaction and individual mental health." The results of this study indicated that the increasing use of the Internet significantly and negatively affect individual's ability to socialize with those around him, and it reduces the ability to communicate with family members in the same house, the study also pointed out that sitting for long periods in front of the computer and the single use of social media leads to depression and social isolation.

Karpinski (2010) aimed to identify the effect of using Facebook on academic achievement in a sample of (219) university students. The results showed that there was a correlation between the time spent by the university student in browsing Facebook and low scores in exams, and it also showed that $(79 \%)$ of the respondents felt that their addiction to Facebook browsing negatively affected their educational achievement.

Suhail and Bargees (2006) aimed to examine the negative and positive effects of excessive use of the Internet on undergraduate students, the sample of the study consisted of (744) university students studied at the University. The results of the study showed that excessive use of the Internet led to educational, physical, psychological problems and a disturbed inter-relationship. 


\section{The study Problem and questions}

Social media addiction has become a phenomenon at all age levels, especially university students, which requires intensifying efforts to understand and address it with providing suitable solutions and counseling, especially as the number of users who are experiencing psychological problems due to the excessive use of social networks is increasing every day. Therefore, the researcher wanted in this study to shed light on the management of time on social networking sites and their role in preventing the risk of addiction to these sites among users through the following questions:

1: What is the role of time management in social networking sites in preventing the risk of addiction to these sites among users?

2: Are there any statistically significant differences at $(\alpha \leq 0.05)$ in the study sample estimates on time management in social media and its role in preventing the risk of addiction to these sites among university students? Attributed to the effect of variables: (gender, college, year ).

\section{1 limitations of the study}

The results related to time management in social networking sites and their role in preventing the risk of addiction to these sites in their users are determined by the validity and reliability of the study tool (questionnaire), but the limits were:

- Spatial Limits: The study was limited to university students in the northern region ( Yarmouk, Jedara, Irbid National, Jerash).

- Time limits: The questionnaire was applied for the academic year (2019/2020).

- Sample of study: The sample of the study was limited to (412) male and female university students, so it can generalize its results to its statistical community only and similar communities.

- Study results are limited by application and analysis conditions.

\section{Terminology of study}

1.Time management: Al-Qa'id (2001: 295) defined time management: as stated on October 24, 2002, document of the Center of Excellence for NGOs:

"The process of taking advantage of the time and personal talent available to achieve the important goals we seek in our lives, while maintaining a balance between the requirements of work and private life and the needs of the body, spirit and mind."

Grisman (2003:1) defines it as "ways and means to make the most of one's time to achieve his goals and create a balance in his life between duties, desires and goals."

Social networking sites: Raymer $(2015: 284)$ stated that it was a system of electronic networks on the World Wide Web that allows the subscriber to create his own site, and then linked through an electronic social system with other members with the same interests and hobbies or communicate with friends University or school.

2.Social Media: are interactive social networks that allow users to communicate anytime they want, anywhere in the world, it appeared on the Internet for years, Social media enables its user to communicate using video, voice, sharing images and other possibilities that strengthen the social relationship between them (Dulaimi, 2011: 183). 3.Social Media Addiction: Dependence on the use of social networking sites for many hours exceeds three hours a day so that the addict can not stop because of the sense of urgency to continue, as indicated by the Saudi study referred to in (Anderson, 2012).

Procedural Definition of Addiction to social networking sites: increasing the hours of using social networks without paying attention to the wasted time and neglect performing other duties, among university students in the northern region.

\section{Methods \& Procedures:}

The study adopts the descriptive survey method to achieve its objectives, as the researcher relied on the questionnaire prepared as a primary source of data, so that it calculated the mean of the items and the standard deviations, as a test to know the time management in social media sites and its role in preventing the risk of addiction to these sites among its users.

\subsection{Study population and sample:}

The study population consisted of (412) students from the universities of the Northern Region (Yarmouk University, Jadara University, Irbid Private University, Jerash University) for the academic year (2018/2019). The sample was chosen based on simple random selection techniques and according to the following demographic characteristics: 
Table 1: Distribution of the sample of the study according to the levels of its variables

\begin{tabular}{|l|l|l|l|}
\hline Variable & Level/category & No. & Percentage\% \\
\hline Gender & male & 178 & $43.2 \%$ \\
\hline & female & 234 & $56.8 \%$ \\
\hline Collage & Scientific collage & 207 & $50.2 \%$ \\
\hline & Humanitarian College & 205 & $49.8 \%$ \\
\hline Years of study & first & 90 & $21.8 \%$ \\
\hline & second & 104 & $25.2 \%$ \\
\hline & third & 143 & $34.7 \%$ \\
\hline & fourth & 75 & $18.2 \%$ \\
\hline
\end{tabular}

\subsection{The study Tool}

After researching the literature and previous studies, the researcher prepared a questionnaire to achieve the objectives of the present study. The questionnaire items were given equal weights on the Likert scale, which consists of five levels to estimate the strength of the procedure carried by the vocabulary of each statement: very high, high, moderate, little and very little. The weights $(1,2,3,4,5)$ are given to the previous levels respectively if the paragraph is positive while weights $(5,4,3,2,1)$ are given to the previous levels in the same order if they bear a negative trend. To interpret the estimates of the study sample on each paragraph of the tool, the following statistical criterion was used:

From 1.00 - less than 1.80 with a very low rating

From 1.80 - below 2.60 with a low rating

From 2.60 - less than 3.40 with a moderate score

From 3.40 - less than 4.20 with a high rating

From $4.20-5.00$ with a very high rating.

\subsection{The validity of the tool}

To ensure the validity of the tool, the significance of the logical validity was applied by presenting it to five specialized educational arbitrators to ensure the suitability of its items, the clarity and relevance were assessed. Certain items were modified based on the suggestions proposed by the arbitrators. Then it was shown to the same arbitrators and another three arbitrators who approved the final form. The correlation coefficients between the paragraph and the tool were calculated. The results were as shown in the following table:

Table 2: values of correlation coefficients between the items of the tool and the overall tool

\begin{tabular}{|l|l|l|l|}
\hline \multirow{2}{*}{ Items } & correlation coefficients & \multirow{2}{*}{ Items } & correlation coefficients \\
\cline { 2 - 4 } & With the tool & & With the tool \\
\hline 1 & $.944^{* *}$ & 12 & $.603^{* *}$ \\
\hline 2 & $.924^{* *}$ & 13 & $.613^{* *}$ \\
\hline 3 & $.907^{* *}$ & 14 & $.729^{* *}$ \\
\hline 4 & $.944^{* *}$ & 15 & $.523^{* *}$ \\
\hline 5 & $.954^{* *}$ & 16 & $.471^{* *}$ \\
\hline 6 & $.853^{* *}$ & 17 & $.697^{* *}$ \\
\hline 7 & $.666^{* *}$ & 18 & $.806^{* *}$ \\
\hline 8 & $.636^{* *}$ & 19 & $.837^{* *}$ \\
\hline 9 & $.525^{* *}$ & 20 & $.840^{* *}$ \\
\hline 10 & $.808^{* *}$ & 21 & $.697^{* *}$ \\
\hline 11 & $.730^{* *}$ & 22 & $.823^{* *}$ \\
\hline
\end{tabular}

Table (2) shows that the correlation coefficients between the items of the tool and the overall tool were appropriate. The correlations between the items of the tool and the fields of study ranged between (0.4-0.9) and are suitable for purposes to achieve the objectives of the current study.

\subsection{The reliability of the tool}

To verify the reliability of the study, the researcher employed the test-retest method on an exploratory sample of

(25) students selected from the study population from outside of the study sample.

The questionnaire was applied to them twice at a time interval of twenty days, and the reliability coefficient 
was calculated by applying the retest, through calculating the correlation coefficient of Pearson (0.83). The internal consistency was extracted by Alpha Cronbach method (85.0). These values of reliability are acceptable for the purposes of the current study.

\section{Statistical procedures}

The researcher used the descriptive survey method by collecting, categorizing and analyzing various data to answer the study questions.

The following statistical methods were applied using SPSS: mean and standard deviations, Cronbach alpha correlation coefficient, Pearson correlation coefficient and Three Way Anova analysis to examine the effect of study variables on social media time management and its role In preventing the risk of addiction to these sites among its users.

\section{Discussion of the results:}

To answer the first question: What is the role of time management in social networking sites in the prevention of the risk of addiction to these sites among users?

To answer this question, the means and standard deviations of the tool items were calculated.

Table 3: Means and standard deviations of the estimates of the study sample members on the items of the tool in descending order according to the mean.

\begin{tabular}{|l|l|l|l|l|l|}
\hline No. & items & Mean* & SD & rank & Grade \\
\hline 8 & $\begin{array}{l}\text { I avoid engaging in conversations and chats because they waste } \\
\text { time. }\end{array}$ & 4.51 & .664 & 1 & $\begin{array}{l}\text { Very } \\
\text { high }\end{array}$ \\
\hline 13 & I feel that my social relations have become weak. & 4.17 & .908 & 2 & high \\
\hline 19 & S.N.S distract me from eating . & 4.01 & 1.019 & 3 & high \\
\hline 11 & I disable most of the ads I see while browsing. & 3.85 & 1.020 & 4 & high \\
\hline 22 & $\begin{array}{l}\text { I suffer from sleeplessness and insomnia at night in due to login or } \\
\text { following-up S.N.S. }\end{array}$ & 3.61 & .882 & 5 & high \\
\hline 21 & I am very tensed when I can't access websites. & 3.07 & 1.012 & 6 & moderate \\
\hline 14 & $\begin{array}{l}\text { Social media occupy my thinking even in my lectures and between } \\
\text { my parents and friends. }\end{array}$ & 2.54 & 1.326 & 7 & moderate \\
\hline 2 & I allocated a specific time to use social networking sites. & 2.51 & 1.406 & 8 & moderate \\
\hline 7 & I stay away from signing up for groups as it is a waste of time. & 2.51 & 1.348 & 9 & moderate \\
\hline 15 & SNS affect my studying. & 2.51 & 1.293 & 10 & moderate \\
\hline 18 & $\begin{array}{l}\text { Following SNS is the last thing I do before bed and the first thing I } \\
\text { do after I wake up. }\end{array}$ & 2.49 & 1.306 & 11 & moderate \\
\hline 9 & I do not feel the passage of time as I browse SNS & 2.47 & 1.401 & 12 & moderate \\
\hline 4 & I make a daily schedule for everyday tasks & 2.46 & 1.421 & 13 & moderate \\
\hline 17 & I use SNS for longer periods of more than four hours. & 2.43 & 1.291 & 14 & moderate \\
\hline 10 & I use SNS for leisure time only. & 2.39 & 1.249 & 15 & moderate \\
\hline 16 & Using SNS distract me from studying. & 2.39 & 1.271 & 16 & moderate \\
\hline 12 & I feel unable to get away from the social media . & 2.36 & 1.209 & 17 & moderate \\
\hline 20 & Following the SNS made me forget my appointment and relations & 2.35 & 1.249 & 18 & moderate \\
\hline 5 & I make the SNS as a reward for myself after every achievement. & 2.34 & 1.349 & 19 & moderate \\
\hline 1 & T take breaks from time to time. & 2.33 & 1.342 & 20 & moderate \\
\hline 3 & I close the device and place it away. & 2.32 & 1.379 & 21 & moderate \\
\hline 6 & I only follow one site to communicate through. & 2.31 & 1.347 & 22 & moderate \\
\hline & Tool as a whole & 2.81 & .698 & & moderate \\
\hline
\end{tabular}

* little (1) and High (5)

Table (3) indicates that the mean of the first field items ranged between (2.31) and (4.51) degree (moderate to very high). Item (8) which states that "I avoid engaging in conversation and chats because they waste time." (mean, 4.51) and (SD.664) with (very high) degree, while item (6) which states "I only follow one site to communicate through."' (mean, 2.31) and (SD ,1.347) and (moderate) degree.

The answer to the second question: Is there any statistically significant differences at $(\alpha \leq 0.05)$ in the study sample estimates on time management in social media and its role in preventing the risk of addiction to these sites among university students? Attributed to the effect of variables: gender, college, year and the academic level.

To answer this question, the means and standard deviations were calculated for the study sample estimates on time management in social networking sites and its role in preventing the risk of addiction to these sites among university students, according to variables (gender, college, year of study) as indicated in Table (4).

Table (4) mean and standard deviations of the study sample estimates on the degree of time management in 
social networking sites and its role in preventing the risk of addiction to these sites among university students as a whole, according to the variable (gender, college, year of study)

Table (4) means and SDs of the study sample based on the degree of time management in SNS and its role in preventing the risk of addiction to these sites among university students as a whole, according to the variable

\begin{tabular}{|c|c|c|c|c|}
\hline variables & category & means & NO. & SD \\
\hline \multirow{2}{*}{ Gender } & male & 3.08 & 178 & .490 \\
\hline & female & 2.61 & 234 & .763 \\
\hline \multirow{2}{*}{ Collage } & Scientific collage & 2.79 & 207 & .736 \\
\hline & Humanitarian collage & 2.84 & 205 & .658 \\
\hline \multirow{4}{*}{$\begin{array}{l}\text { Year of } \\
\text { study }\end{array}$} & first & 2.85 & 90 & .649 \\
\hline & second & 2.99 & 104 & .667 \\
\hline & third & 2.53 & 143 & .691 \\
\hline & fourth & 3.09 & 75 & .620 \\
\hline
\end{tabular}

Table (4) indicates that there are apparent differences between the means based on the estimates of the members of the study sample on the study tool according to the variable (gender, college, academic level) .To determine the statistical significance of these apparent differences the "A three-way ANOVA" was applied, as shown in Table (4).

Table 4: Analysis of the A three-way ANOVA of the means of the Study Sample on the Time Management

Degree in Social Media Sites and its Role in Preventing the Addiction Risk of these Sites among University Students as a whole, by Variable (Gender, College, year of study)

\begin{tabular}{|l|l|l|l|l|l|}
\hline Variable & SS & DF & MS & F value & P value \\
\hline Gender & 14.630 & 1 & 14.630 & 40.009 & .000 \\
\hline Collage & .456 & 1 & .456 & 1.248 & .265 \\
\hline Academic year & 16.911 & 3 & 5.637 & 15.415 & .000 \\
\hline Error & 144.803 & 396 & .366 & & \\
\hline Total & 3464.132 & 412 & & & \\
\hline Modified total & 200.160 & 411 & & & \\
\hline
\end{tabular}

* Statistically significant at the level of statistical significance $(\alpha=0.05)$

From Table (4) we can note that:

- There are statistically significant differences at the level of statistical significance $(\alpha=0.05)$ of the study sample estimates on time management in social media sites and its role in preventing the risk of addiction to these sites among university students as a whole, according to the variable (gender) and the differences were in favor of males. - There is no statistically significant difference at the statistical significance level ( $\alpha=0.05)$ of the study sample estimates of time management in social media sites and its role in preventing the risk of addiction to these sites among university students as a whole, according to the variable (college).

- There is a statistically significant difference at the level of statistical significance $(\alpha=0.05)$ of the study sample estimates on time management in social media sites and its role in preventing the risk of addiction to these sites among university students as a whole, according to the variable (the academic year) to identify the significance of differences on Variable academic year, Scales Comparisons were made using the Sheff'e Test, as shown in Table 5 . 
Table 5: Dimensional comparisons using Sheff'e Test for the study sample estimates on time management in social media sites and its role in preventing the risk of addiction to these sites among university students

\begin{tabular}{|l|l|l|l|}
\hline First & second & -.14 & .477 \\
\hline & third & $.32\left(^{*}\right)$ & .001 \\
\hline & fourth & -.24 & .100 \\
\hline Second & first & .14 & .477 \\
\hline & third & $.46\left(^{*}\right)$ & .000 \\
\hline Third & fourth & -.10 & .757 \\
\hline & first & $-.32\left(^{*}\right)$ & .001 \\
\hline & second & $-.46\left(^{*}\right)$ & .000 \\
\hline Fourth & fourth & $-.56\left(^{*}\right)$ & .000 \\
\hline & first & .24 & .100 \\
\hline & second & .10 & .757 \\
\hline & third & $.56\left(^{*}\right)$ & .000 \\
\hline
\end{tabular}

* Statistically significant at significance level $(\alpha=0.05)$.

Table (5) correlated to Post Hoc Comparisons shows the differences between the first-year category and the third-year category in favor of the first, as well as the differences between the category of the second year and third year category and the differences in favor of the second year, as well as the differences between the fourth year and third year category and the differences in favor of a fourth year.

\section{Conclusions and recommendations}

\subsection{Results}

The first question: The results of the study showed that the role of time management in social networking sites in preventing the risk of addiction to these sites among their users ranged from moderate to very high degree.

The second question: The results showed that there was a statistically significant difference in the study sample estimates on time management in social media sites and its role in preventing the risk of addiction to these sites among university students as a whole, according to gender variable and the differences were in favor of males. - There is no statistically significant difference for the study sample estimates on time management in social networking sites and its role in preventing the risk of addiction to these sites among university students, according to the college variable.

- There is a statistically significant difference to the estimates of the members of the study sample on the management of time in social networking sites and its role in preventing the risk of addiction on these sites among university students as a whole, according to the variable of the years of studying.

\subsection{Conclusion}

Finally, it was found that social media is a great cultural achievement that a person can decides how to benefit from and how to avoid its risks. But at the same time, we can't deny the importance of the joint effort that should be invested and integrated to provide advice and support to those people who are unfortunately addicted to these social platforms. Actually, most of these people are the university students, who because of their increasing desire to use modern technology and communication networks as a result of some psychological and social factors represented in the desire of young people to establish relationships and friendships with others in various parts of the world. But their overuse of these platforms may affect them negatively and cause frustration or isolation.

The results of the study showed that time management on social networking sites has a role in preventing the risk of addiction to these sites among their users and it ranged from (moderate- very high). The study also showed that there were statistically significant differences for the study sample estimates on time management in social networking sites and its role in preventing the risk of addiction among its users from college students as overall attributable to the gender variable and the differences were in favor of males and the school year variable. The results also showed that there were no statistically significant differences for the sample estimates due to the college variable.

\subsection{Recommendations}

In the light of the results of the current study recommended the following: -

- Conducting studies like the current study on university students to find other ways to prevent the risk of addiction on social networking sites and compared it to the current study.

- Seeking out for the bright side of these means in terms of use; employ them for the benefit of the person and the nation in all aspects. 
- Organizing training workshops and holding awareness lectures that highlight the danger of addiction to these sites.

- Establishing a general social system to occupy leisure time for young people, especially during summer and other vacation periods, such as setting up programs for clubs to be joined by young people to spend leisure time in addition to doing what benefits them and their community.

\section{References:}

Abu Hadrous, Y, M. (2016). The effectiveness of a behavioral counseling program in treating addiction on Facebook, among a sample of adolescents. Zarqa Journal for Research and Humanities Studies, Vol. 16, No. 3

Adarbeh, M (2006). Time Management for Principals and Principals of the UNRWA Relief Agency Western. Master Thesis. Palestine: Birzeit University.

Grisman, E (2003). The Art of Time Management: How Do Successes Manage Their Time? · Riyadh: Translating the House of Ideas International Publishing \& Distribution.

Hamdi, O.(2015). Article Ten Ways to Reduce Social Media Waste Time. - April 25. Https://www.techwd.Com $/ w d / 2015 / 04 / 25 / \%$ EF\%BB\%BF\%D8\%B9

Al-Helo, C. (2018). Social media and its impact on the psychological condition of university students: a multicountry comparative study, International Journal of Educational and Psychological Studies. Vol. 3, p. 2, 2018.

Marakchi, M (2014) .Use of social networks and its relationship to a sense of psychological unity University students (- Facebook - model). Complementary note to obtain a master's degree in psychology. Algeria: Biskra, Mohamed Khader University.

Meligi, A.(2015). Media and global social networks. Alexandria: Education House University.

Naif, D (2018). Are you addicted to social networks ?. April 24, 2018, — by admin — Leave a Comment https://www.alweeam.com.

Najem, S (2001). Electronic Publishing New Technology Towards New Horizons.

Rafaya, J (2016). Networking sites, consummate time thieves. Oman: Middle East Online. First Published: 2016$10-24$

Al-Shimi, D (2009). Facebook addiction, psychological and social factors: a psychologist's diary http://www.3ainalabokra.com

Waleed, R (2019) .Reasons for social networking addiction by: Ruqaya Walid - Other Update: 10:41, May 9 https://mawdoo3.com

Wikipedia, the free encyclopedia (2010) Internet addiction. HTTP: / en. Wikipedia. OR/wiki/2010.

Foreign references

Antony, M. (2016). "20 Popular Social Media Sites Right Now" Small

Business Trends Retrieved 18-7-2017. Edited

Boyd, M.D. and Ellison.(2007). Social Networks Sites: Definitions, History and scholarship, Journal of ComputerMediated Communication, 13 (11).

Elise, M .(2017). "The Top Social Networking Sites People Are Using" Livewires Retrieved 18-7-2017. Edited.

Karbiniski, A. (2010).Facebook and the technology revolution, N, Y Spectrum Publications.

Kraut, R., Lundmark, V., Patterson, M., Kiesler, S., Muko.T. and Scherlis, W. (2007). " Internet Paradox: A Social Technology that Reduces Social Involvement and Psychological Well-being." Journal of American Psychologist Sept., vol.53, No.9, p.1017-1031.

Mecheel, V. (2010).Facebook and the invasion of technological communities, N, Y, New York.

McClellan, J.(2012). Six ways to Kick Your Facebook Addiction http://mashable.com, 12/6/2013.

Raymer, K. (2015). The effects of social media sites on self-esteem”. Theses and Dissertations. P. 284.

Sharifah S, S.Z., Siti Zobidah O., Jusang, B, Mohd, N O (2011). Facebook Addiction among Female University Students. Revisited de Administration Students. Revisited de Administration Behavior. V.3.N2 (7), 94-10.

Suhail, k., and Bargees, z. (2006). Effects of excessive Internet use on undergraduate students in Pakistan. Cyber Psychology and Behavior, V.9, N.3, p.p.297-307. 